\title{
A Herminio Barreiro, na memoria
}

Daniel PINO

\section{Ben querido Herminio:}

Narciso de Gabriel convídame a colaborar no número monográfico que Sarmiento, tantos anos por ti dirixida, pensa dedicar á túa obra, longa, fonda e entrañable; e á túa vida, para a nosa tristura, curta. Dirixo esta carta a esoutro lugar onde agora te atopas, que non é outro que o da MEMORIA. Da prominente presenza na miña particular Memoria e, estou certo, na de todos os teus amigos a mancheas. Tamén na dos bos e xenerosos. Na daqueles que tiveron a ledicia e a honra de te coñecer, na dos que tiveron a dita do agasallo do teu maxisterio, directamente ou a través da túa obra profesional. E, presumo, de todos os que aínda sen te tratar fixeron da súa vida, coma ti, unha defensa permanente e -afortunadamente - utópica a prol da liberación e a dignidade do xénero humano. Tan necesaria para podermos avanzar, mesmo cos inevitables pasos atrás a que obrigan complexas contradicións inherentes ao desenvolvemento das sociedades humanas. Ti confiaches sempre en que os retrocesos non deixan de ser o alicerce dos futuros avances. Soubeches concordar a firmeza radical na defensa das túas ideas cunha exemplar tolerancia para coas ideas dos outros. $E$ antes de que tan prematuramente entrases nesa MEMORIA, o teu foi sempre a ansia do coñecemento da complexa realidade social; non tanto para recrearte nela, canto para poñelo ao servizo da súa transformación. Tanto da realidade do noso común país, da Galicia, porque entrara en ti por todos os poros da pel, como do Mundo enteiro: desas dúas realidades fuches quen de deixar páxinas de fondura e beleza. Outro tanto na mestría do teu discurso oral (cando a vida era difícil, escura e funesta, ou cando asistimos hoxe a unha xeneralizada mediocridade). Un mundo que, parafraseando a Ciro Alegría, xa non é tan largo por máis que siga a ser alleo. Nese empeño déchelo todo con fartura. Por iso xa tes garantido un asento de privilexio na inmortalidade.

Dito 0 anterior —que consideraba imprescindible-, logo de debullar sobre o que escribir encol de ti para a ocasión, tendo en conta que o meu único mérito é ser amigo teu de vello, pensei nesa verba tan de ti que son os recordos. Pero diante da imposibilidade de recordar unha amizade de medio século en menos de 20.000 caracteres, xulguei que debería facelo con algúns recordos daquela primixenia vida en común da primeira metade dos anos sesenta, en Madrid e tamén na nosa Terra.

Son recordos que non me doen, porque estiveron no cerne mesmo de quen cheguei a ser eu mesmo. Para min, o único recordo de ti que me doe é o de non poder seguirmos agora a analizar, debater, lembrar e, mesmo, a rirnos do divino e do humano, como fixemos vai para dez meses na túa casa de Santiago, en compaña de Luís Cochón, de Carmen 
e dos teus (Merche e David -Sonia non estaba-), sabedores todos, ti e nós, de que posiblemente sería a derradeira vez de evocar e analizarmos xuntos, tentando non amosar -nin ti nin nós- a dor que sentíamos.

Adiántoche que non son recordos transcendentais, pero son unha mostra dos que alicerzaron a nosa particular amizade ao longo de cincuenta anos e que agora acoden ao meu chamado. No meu libro de poemas No leme das lembranzas, era eu quen de gobernar os recordos, porque eran as miñas propias e íntimas vivencias. Mais agora, como facer tal coas lembranzas de nós os dous? Só se me ocorre acudir, como o fan case todas as historias, ao comezo.

Un dia de inverno -Nadal de 1960 ou Xaneiro de 1961, non podo precisar- presentounos Manolo Domínguez, o amigo común que, coma ti, tan cedo nos deixou. Foi na rúa San Bernardo, por fronte do "Viejo caserón" da Complutense, que daquela acollía a miña Facultade; a uns cen metros dos Mariscos, o mítico café do parladoiro da xente de Brais Pinto, os sábados pola tarde. Polo teu convite acudín tamén eu dende esa semana a case todos eses encontros co seu bálsamo de sentírmonos na Terra malia a distancia. Da túa man coñecín a Patiño, a Bautista, a Arias, a Fdez. Ferreiro... Un tempo despois a Novoneyra, a Bernardino Graña, a Alexandre Cribeiro...; e a tantos que por aquel vello café apareceron nos anos sucesivos.

Ese mesmo ano, e por ese tempo, coñecemos a Santiago Montero Díaz, para min, unha das mentes máis lúcidas -e tamén contraditorias- da intelectualidade galega e española do século XX. Este noso país tan desagradecido cos seus mellores fillos, débelle un recoñecemento, non cres? Nunca esquecerei as súas "clases maxistrais", nin as que daba na aula, nin moito menos, as que a uns poucos paisanos elixidos nos impartía dende as dúas da tarde ata as dúas ou tres da mañá, naqueles vía crucis polos bares de Argüelles, que el escollía, á saída das clases oficiais de Historia de las Religiones, en Filosofía, logo de fuxirmos con el dos moscardóns pola terraza da Facultade. Eses días non xantabamos máis que as tapas que poñían cos viños. Lémbraste daquela ocasión en que nos deu un repaso pola historia para demostrar que Galicia nunca fora consquistada?

Ao ano seguinte, 1962, foi cando nos detiveran aos dous, logo de participar nunha manifestación, por suposto prohibida, da que xa non me lembro exactamente os motivos da convocatoria, máis alá da sempre presente loita pola liberdade. Seguírannos logo de lle botar unha man a Lourdes Ortiz, tirada no chan a porrazos polos grises. Dixemos que acudiramos a ver a Volta Ciclista a España - que efectivamente ía pasar pola Cidade Universitaria e que se pretendía cortar. De aí non nos movéramos diante dos interrogatorios policiais. Ese día, 7 de maio, selouse aínda máis a amizade cuxos piares se chantaran 0 ano anterior. Lémbrome dos esforzos de Uxío Novoneyra para tentar que nos soltaran, falando con Figueira Valverde, daquela Alcalde de Pontevedra, que estaba en Madrid por mor dun evento deses que agora chamarían de promoción turística da cidade. Chegara Uxío a Peñalara a iso da unha da madrugada, todo compunxido porque Don Xosé dixera que nada se podía facer por aqueles dous ex-alumnos do seu Instituto. Non sospeitaba 
Uxío que nos ía atopar na cafetería. A iso das doce da noite e logo de nos impoñer unhas fortes multas xa nos soltaran e estabamos a celebrar a liberdade con Coia e Patiño.

No comezo do verán dese ano 62 non puideches examinarte de Románicas por unha miserable falla administrativa, tendo que deixar os estudos de Gramática Histórica con Lapesa - de quen tanto me falabas - para cambiar de especialidade ao ano seguinte. Todo hai que dicilo, para maior gloria da Historia da Pedagoxía. E tampouco non puideras ir a Munich como tiñas pensado. A retirada dos pasaportes que comportara a nosa detención e multa, impedíranche aproveitar a beca que tiñas concedida. Eu non volvín dispor do pasaporte ata 1977, quince anos despois

Estas dúas cousas tíñante desesperado. Mesmo aceleráronseche os, de seu, frecuentes pesadelos nocturnos, nos que te erguías e falabas coa lóxica de quen estaba esperto, ata que aparecía o absurdo, o meteorito delator de que estabas durmido; soños que te cabreaban logo de se esfumar a realidade do soñado, sobre todo cando o soño fora do teu agrado. Unha noite, a iso das cinco ou seis da mañá, eu non me deitara —eran os exames finais- e ti, comezaches a berrar: Dispara, coidado, dispara! Era tal a axitación —movéndote para un lado e para outro da cama-, que te deches un golpe forte contra o canto dun dos banzos de ferro do metálico. Sentaches na cama e viches a perna a sangrar. E dicías: É verdade, é verdade. Sen embargo parecía satisfacerche a ferida. Mais, como o sangue era abondo esperteite. Cabreáraste, nesta ocasión, porque estabas a soñar que te feriran, mentres loitabas en Praia Girón por repeler a invasión ianqui contra a Revolución cubana, á que defendiches sempre, ata o momento de marchares para o lugar da MEMORIA. Dez anos despois gañaches un concurso literario convocado por Radio Habana, cuxo tema era o significado daquela epopea para as loitas de liberación dos países de Latinoamérica naquela década. $E$ fuches á túa querida Cuba a recibires o premio. $E$ viches e saudaches a Fidel. Á volta, en Madrid, cando discutimos sobre os problemas da Illa, fixéchesme unha boa radiografía do que estaba a suceder alí. Pero remataches por me dicir: Eu con Cuba non podo ser crítico.

Ao remate daquel curso 61-62, no que tantas cousas pasaran, incluídas as primeiras grandes folgas contra o réxime, compensamos a imposibilidade de saír do país cos encontros do verán en Pontevedra, con Cochón, Domínguez, Fortes, Falcón... Da túa man coñecín o Salnés e, por descontado, ese néctar de ouro pálido que é o Albariño monovarietal, da túa Terra. En Sisán, Padrenda, Nantes, Bordóns, Noalla, Feifiñáns..., ti sempre sabías onde catalo bo. Pero nada como o do teu tío Gilberto e, máis tarde, o de teu pai.

Nada che dixera, porque non se podía, que antes de rematar ese curso, eu entrara a militar no Partido Comunista. Esa circunstancia non coutou un verán feliz, no que tentabamos concordar as nosas urxencias xuvenís plenas (amores, sexo cando cadraba, festas, viño...) con lecturas apresuradas de obras de autores que deixara fóra a educación oficial, por caso, a Marx e Engels, a Sartre ou a Camus, a Faulckner ou a Dos Passos, a Ortega ou a Sánchez Albornoz; a moitos clásicos rusos, a Bertolt Brecht ou a Luckas, a García Lorca ou a Miguel Hernández; máis tamén aos nosos: a Castelao, a Otero Pedrayo ou a Dieste. Aparte, claro está, de poñernos ao día con autores máis daquel momento: Sánchez 
Ferlosio ou Juan Goytsolo, Celso Emilio ou noso entrañable amigo Novononeyra, con quen estarás agora a parolar en paseos por unha outra Alameda, a da MEMORIA onde os dous morades. Todo un ano de lecturas a ser comentadas, debulladas, sobrios ou ebrios, no decurso do 1962 que, sen nós o saber aínda, ía ser un ano farturento dos da década prodixiosa: $2^{\text {a }}$ Declaración da Habana, Independencia de Arxelia, Concilio Vaticano II, Bloqueo de Cuba por EE.UU., "Love Me Do" dos Beatles, morte de Marilyn Monroe...

E, para rematar ese ano, aquel accidente xa en tempo de Nadal, cando guiando eu, envorquei o Seiscentos do teu pai, logo dunhas cantas voltas de campá, no que viñamos de pasar o serán catando os magníficos albariños do teu tío Gilberto e iamos a 0 Grove a ver á moza do Luís daquel ano. Chamábase Olga? Lembro dúas cousas do accidente. A primeira, o susto que nos dera o Luís, que ía no asento de atrás, cando despois dun instante eterno, naquela noite pecha, ningún de nós se atrevía a preguntar polo estado dos outros, e el coa súa voz de barítono, para a ocasión, cavernosa, nos dixera: Fáltame, fáltame, fáltame... [novo e espectante silencio]; fáltame un zapato, hostia! Botámonos os tres a rir ás gargalladas. $E$ tamén me lembro do comentario tan do teu pai cando lle demos a nova de que co accidente o deixabamos sen un instrumento capital para o seu traballo, alomenos, para tres ou catro semanas: "Foi mellor que fose aquí en Sisán que na curva da Lanzada." Aquel 22 de decembro do ano 1962, verdadeiramente, tocáranos a lotaría.

O ano seguinte, 1963, en abril, foi 0 ano da nosa memorable viaxe a Andalucía en auto-stop, decidida así de súpeto na Estación de Atocha, na despedida que uns cantos amigos facíamos a Domínguez, que se ía incorporar á súa Cátedra de Literatura, logo da oposición que viña de gañar, con obtención de praza no Instituto de Cabra. Marchaba tan tristeiro cara o que el consideraba un desterro, que alí mesmo lle prometemos irmos ti e mais eu en auto stop a Cabra o día seguinte. Ti xa estiveras en Andalucía, penso, o ano anterior, acompañando a aqueles progres americanos, Walter e Katherine, que eu coñecera na facultade.

Manolo non o creu ata que nos veu alí dous días despois. Como na Odisea, o de menos fora chegarmos a Itaca-Cabra, por máis que esa era a intención. 0 importante, como tantas veces adoita acontecer, foi a propia viaxe: 0 descubrimento dun país tan distinto do noso, cheo de contradicións que, dende aquela, comezamos a comprender. A min serviume o descubrimento para logo comezar a comprender a todos os pobos do mundo. Nada especial acontecera ata Puerto Lápice, onde nos deixara a iso das catro da tarde 0 coarto ou quinto condutor que nos collera. Pero alí na chaira manchega pasaban as horas e aveciñaba a noite. Eu desesperaba. Ti, como sempre, confiado: "Non te preocupes, está a punto de vir o 'golpe de sorte' que decote se ten que dar". Pois si, a iso das seis e media parounos un coche con sombra, como lle chamabas aos escasísimos coches que daquela se podían ver con cristais escuros. Era un ID-19, con matrícula francesa, aquel coche de deseño revolucionario (aínda hoxe o semella) coñecido como Tiburón, que ata entón eu só vira nas películas. Detívose maxestoso e sen máis o condutor colleunos. Entramos axiña, non se fose arrepentir. 
De primeiras o señor, duns 40 anos, case non falaba, máis alá dos monosílabos de resposta ás nosas tímidas preguntas. Tomámolo -0 acento era delator, malia a cativa oralidade - por un señorito andaluz. Quen senón ía ter un coche así nuns tempos onde calquera coche era un luxo para moi poucos? Logo comprobamos que estabamos nun erro. Ao pasarmos Despeñaperros e contemplar aqueles ondeados outeiros de Jaén preñados de oliveiras, díxonos: "Veij ujtede todoj esoj olivo. Puej, posiblemente sean de un solo señó. ¿Y sabeij cuanto gana, como muxho, un jornalero?; 25 pesetaj ar día." Evidentemente, non era un terratenente. Dende aquel momento falou e falou. Que se marchara para Francia, porque alí non había vida para un home. Que agora era chofer dun empresario francés. Viña só para recollelo no Aeroporto de Sevilla e así poder dispor o seu xefe do coche e do condutor durante a Feira de Abril. Tentou convencernos para que fósemos con el e logo de vivir a Feira, poderíamos ir visitar o noso amigo. Moi ao noso pesar, dixémoslle que nos era imposible. Deixounos en Córdoba a iso das oito ou oito e media.

Alí, collemos aquela pensión situada preto da praza do concello (que case nin usamos, pois deitamos ás sete da mañá e erguemos ás oito para continuar camiño). Saímos axiña con intención de visitar a Mezquita. Preguntamos, lembraraste, a aqueles dous homes aínda novos que responderan: "Noshotro vamoj pallá". O que non agardabamos é que cando alcanzamos a Mezquita fosen mais das cinco da madrugada. Era fin de semana e paráramos en toda canta tasca había no camiño, convidados por un condutor de camión que coñecía e gustaba de Galicia e un traballador da construción. Non fomos quen de pagar as copas deses marabillosos finos cordobeses en ningunha das tascas, nin tan sequera nunha da que os donos procedían de Mondariz. Moi botados para diante, non se asustaban con verbas como socialismo, anarquismo ou socialismo (logo dunhas horas inxerindo finos), ata o punto de que para nós, aprendices de revolucionarios, esa noite, xunto con outros encontros semellantes na viaxe, servira para nos convencer de que unha experiencia como a cubana de tres anos atrás, en España tería que comezar -e pensabamos que axiña - por Andalucía, o lugar onde as desigualdades eran tan evidentes e explosivas. Que equivocados estabamos! Pero aquela semana andaluza comprometéranos (aos dous) aínda máis na vontade de loitar contra o fascismo a prol dos dereitos das persoas e dos pobos.

Para a nosa desgraza, o ditador morreu na cama e, mesmo, a democracia representativa chegou da man dunha transición pactada e non dunha ruptura democrática. As consecuencias dese modo de cambiar, aínda as estamos a ver nestes tempos, máis de trinta anos despois. $E$ diso tamén falamos nas últimas veces que nos vimos.

Ese ano, en maio, funme vivir nos meses finais do curso, como no ano anterior, á vosa pensión da rúa Infantas: á que chamabades "La extraña prisión de Huntleigth", en loa e semellanza con aquela película de Robert Day, interpretada por Peter Sellers e David Lodge. Quedaba un sitio baleiro naquel labirinto da bufarda que daba á Praza de Bilbao (que non Glorieta) á que hoxe chaman Vázquez de Mella. Chegaramos a parar nela vinte e tres persoas, de todo tipo e condición. Dos amigos, que me lembre, estabades ti, Patiño, Falcón, Manolo Coia (que collera un dos faios onde non se podía estar de pe ao que alcuñamos 
como a cápsula espacial) ..., e Méndez Ferrín e Bernardino Graña cando viñan por Madrid. Dos poucos meses pasados alí por min (non chegaran a tres) teño infindos recordos. Máis son inesquecibles aquelas madrugadas nas que tiñamos que facer unha cadea humana para rescatar ao Raimundo do estreito e empinado tellado que mediaba entre 0 ático e 0 paramento que daba á praza, situado a máis de vinte metros de altura, ao que accedía con dificultade pola estreita xanela que ventilaba a habitación, logo de se empapar de alcohol e de rachar algún cadro (do período informalista), que xa non lle gustaba. E ti e máis eu a xogármonos a vida para salvar a segura caída ao baleiro do noso inesquecible Patiño, o grande amigo avivezador de todo o mundo cultural galego daquel tempo na capital de España, que tan costa arriba levou sempre o traballo no Banco.

Recordo tamén as noites en Ohio, a cafetería da rúa Fuencarral, ou en Puebla, na rúa deste nome, que eran lugares de retirada, ata chegar a Peñalara, ao mesmo pé da nosa pensión, a tomar o último cubata, se algo de cartos nos quedaba a algún. E da pastelería que había tamén na rúa Puebla, onde mercabas ti os hojaldres de merengue, dos que tanto gorentabas. Aparte do Parladoiro dos Mariscos, era nestes sitios onde adoitabamos analizar en común as informacións que cada quen obtivera ao longo do día, sobre a situación política española e mundial, ou conversar sobre a última película que víramos, as conferencias de Aranguren, de Montero Díaz, de Álvaro Cunqueiro, os recitais de Salvatore Quasimodo ou de Carlos Oroza, ou calquera exposición de interese á que nos levaba Patiño.

Ese ano, á volta de vacacións, no inicio do seguinte curso, buscamos ti e máis eu outra pensión. Decidimos alugar unha na rúa Luna, preto da Gran Vía, xa que logo, sen saírmos do barrio. A pensión estaba ben, limpa e confortable. A patroa, que rebordaba touciño en demasía, díxonos que traballaba na policía, en pasaportes, que o seu home era comisario e o seu fillo oficial de prisións. En realidade o sereno dixéranos de que fora madama dunha casa de citas e que o comisario primeiro a retirara e despois a "enchufara" naquel posto. A min, a proximidade de tanto membro de corpos represivos ao redor fixo que me entrara 0 desacougo, por non dicir pánico, e díxenche que ía buscar outro sitio. Foi un inmenso erro, hoxe téñoo claro. Onde ía estar máis seguro que vivindo nun sitio como aquel? Funme para un piso lonxe do barrio, en Cuatro Caminos.

Seguimos en contacto, pero a miña implicación crecente na política clandestina, a aceleración nos estudos dos dous e a túa decisión de facer o servizo militar en aviación para cumprilo en Madrid, fixo que os nosos encontros xa non foran a diario. Ben que 0 sentín. A esas alturas, xa sabías da miña clandestina dedicación. Compartíala, pero non podías asumila nese momento do mesmo xeito nin eu fixen a máis mínima presión para tal, sabedor de que o risco non era poñerte en perigo só a ti, senón á túa familia, a que quixen e quero como propia.

Aqueles inicios da miña vida realmente adulta remataran coa detención e condena. Nos anos pasados na cadea pensei abondo nas nosas conversas daqueles catro anos. Decateime do moito que significara o terte coñecido. Coido que a miña madurez temperán, máis que a ninguén, se debe á nosa relación. 
Ti, mentres, remataras a licenciatura de Pedagoxía e casaras con Merche, á que eu coñecera dende que comezaras a saír con ela, e marcharades a Francia, país - a máis do noso- que como Cuba ou a URSS era tan querido para ti, a desenvolver un lectorado de español. Eu tiven noticias túas a través das cartas da miña nai á prisión e dunha visita que fixeras a Carmen en Madrid. Creo que nunca cheguei a dicirche o meu contento por saber que estabas fóra e que as gadoupas do fascismo non te ían coller.

Volvemos vernos en 1967. Gardo aínda o calor da túa aperta cando nos reencontramos. Vos regresarades a Madrid e viviades en Aluche. Foi unha amiga de Merche a que nos deixou un piso baleiro para pasarmos a nosa noite de vodas. Era o 30 de Xaneiro do 68. Outro ano no que acontecerían importantes cousas, e viñan de asasinar o Che Guevara uns meses antes. Nós, logo de facer eu a mili en Vigo e de nacer a miña filla Marta, voltamos para Madrid no outono do 69 , onde estivemos ata finais do 73 . Retomamos a relación con asiduidade neses catro anos, como despois cando coincidimos por case unha década en Santiago.

Porén, estas son xa outras épocas de relación intensa das que falaremos noutra entrega, se é que hai ocasión. Coido que xa me pasei en extensión e non sei que me dirá o Narciso.

Ata sempre, unha infinda aperta, compañero del alma, compañero.

Vilaxoán 28 de agosto de 2011.

Daniel Pino

P.D. Non sei se ata aí chegarán as novas do fútbol. Por se non é así, quero que saibas que dende que te fuches o Barça leva gañado catro títulos: Liga, Champions League, Supercopa de España e Supercopa de Europa. E cada trofeo que gaña penso no que te aledarías ti. 